\title{
A PARAMETRIC STUDY OF ACTUATOR REQUIREMENTS FOR ACTIVE TURBINE TIP CLEARANCE CONTROL OF A MODERN HIGH BYPASS TURBOFAN ENGINE
}

\author{
Jonathan L. Kratz \\ NASA Glenn Research Center \\ Cleveland, $\mathrm{OH}$, United States
}

\author{
Jeffryes W. Chapman \\ Vantage Partners, LLC \\ Brook Park, OH, United States
}

\author{
Ten-Huei Guo \\ NASA Glenn Research Center \\ Cleveland, $\mathrm{OH}$, United States
}

\section{ABSTRACT}

The efficiency of aircraft gas turbine engines is sensitive to the distance between the tips of its turbine blades and its shroud, which serves as its containment structure. Maintaining tighter clearance between these components has been shown to increase turbine efficiency, increase fuel efficiency, and reduce the turbine inlet temperature, and this correlates to a longer time-on-wing for the engine. Therefore, there is a desire to maintain a tight clearance in the turbine, which requires fast response active clearance control. Fast response active tip clearance control will require an actuator to modify the physical or effective tip clearance in the turbine. This paper evaluates the requirements of a generic active turbine tip clearance actuator for a modern commercial aircraft engine using the Commercial Modular Aero-Propulsion System Simulation 40k (C-MAPSS40k) software that has previously been integrated with a dynamic tip clearance model. A parametric study was performed in an attempt to evaluate requirements for control actuators in terms of bandwidth, rate limits, saturation limits, and deadband. Constraints on the weight of the actuation system and some considerations as to the force which the actuator must be capable of exerting and maintaining are also investigated. From the results, the relevant range of the evaluated actuator parameters can be extracted. Some additional discussion is provided on the challenges posed by the tip clearance control problem and the implications for future small core aircraft engines.

\section{INTRODUCTION}

Turbine tip clearance refers to the distance between the turbine blades and their containment structure. The tip clearance changes over the course of a flight due to thermal expansion, centrifugal forces of the spinning components, and the mechanical loads applied to the structures by aerodynamic forces and internal stresses. Axisymmetric tip clearance variations are the most significant and include the contributions of thermal expansion and the elongation of moving components due to axisymmetric thermal and mechanical loads. Capturing these components of the tip clearance variation is the focus of the tip clearance model used in this study.

A physical explanation of the variation of the tip clearance gap begins with any change in engine operating condition. Consider an increase in power. As the rotor and blade increase in speed, the centrifugal force exerted on these components increases causing them to expand. Additionally, as the temperature in the gas path increases the turbine components heat up and expand. Due to differences in size, geometry, materials, and heat transfer rates, the components of the turbine expand at different rates and reach different steady-state deformations. Note that throughout this paper deformation will be used to characterize an elongation or contraction of a turbine component. This is not to be confused with twisting or bending.

Deformation of the blade and rotor occurs relatively quickly due to acceleration of the high pressure spool (HPS). The blade deformation is accelerated further by its relatively fast thermal expansion because of its relatively low mass and large surface area, and its direct exposure to the hot gas path. The rotor and the containment structure around the turbine are larger and experience weaker heat transfer leading to much slower thermal transients and therefore slower expansion. These differences in magnitude and rate of expansion, particularly between the internal engine components and containment structure, create 'pinch points' where the tip clearance is significantly reduced during fast accelerations of the engine that are accompanied by rapid changes in the gas path temperature. These pinch points lead to conservative and less efficient design decisions.

Modern commercial gas turbine engines employ slow acting thermal management techniques for controlling the tip clearance in the high pressure turbine (HPT) and low pressure turbine (LPT) [1]. Due to the lack of tip clearance sensors 
capable of withstanding the harsh conditions of the turbine for a long duration, these control systems rely on a scheduled control logic [2] that requires larger than necessary tip clearance gaps as a result of the uncertainty associated with the lack of feedback. The control system typically consists of a number of bleeds and secondary flow passages. These passages take air from cooler sections of the engine's gas path, such as the compressor and fan duct, and circulate it through passages around the turbine containment structure to induce thermal contraction that shrinks its radius and reduces the tip clearance gap. The dynamics of these control systems are slow compared to the deformation dynamics of the blade and rotor. These systems are also limited by the temperatures and mass flow rates of the bleeds that supply the cooling passages. For these reasons a conservative tip clearance is built into the turbine to avoid blade rubs during fast transient maneuvers such as takeoff and in-flight re-accelerations. This conservative design results in a larger tip clearance during cruise than is necessary. Seeing that commercial aircraft spend most of their time flying at the cruise condition there is ample room for performance improvements over the lifetime of the engine. Also consider that as the turbine components degrade over time, the blades erode and the tip clearance gap widens leading to a lower turbine efficiency. The current conventional tip clearance control approach is not easily adapted to handling component degradation by adjusting to the increased gap. This not only reduces performance but leads to faster degradation as the turbine must operate at a higher temperature to achieve the same thrust.

It is well established that tip clearance is directly related to turbine efficiency, which can impact fuel consumption and the turbine inlet temperature. Reduction in fuel consumption has obvious benefits in savings on fuel as both a natural resource and a monetary expenditure. It has been shown that the rate of degradation of turbine blades is at its maximum when turbine temperature is at a maximum [3]. For large commercial engines it is a rule of thumb that a 10 mil reduction in tip clearance equates to an increase in turbine efficiency of $\sim 1 \%$ and a $\sim 10^{\circ} \mathrm{C}$ reduction in the turbine inlet temperature, which can mean a reduced thrust specific fuel consumption (TSFC) and a longer time-on-wing for the engine [4]. Reduction in the turbine inlet temperature can not only extend the life of the engine components but also reduce the maintenance costs for the engine over its lifespan. To realize these benefits a fast response actuator with a closed loop controller is desired [2]. The potential benefits of active clearance control are well established, the real issue is determining how actuation should be implemented in order to benefit the engine's performance at the system level.

Modern gas turbine engines do not utilize fast response active tip clearance control. Reasons include the lack of robust high temperature sensors, actuator weight, sealing issues and various other challenges [1]. However, there is interest for future engine applications. The future of commercial gas turbine engines is moving toward ultra-high bypass ratio turbofan engines [5] with a small ultra-efficient core that demands a higher turbine inlet temperature and highly loaded turbomachinery [6]. These changes could exacerbate the tip clearance problem by influencing faster deformation rates for the turbine structure. Furthermore, the smaller annulus height of the small core engines will demand a smaller tip clearance be maintained in order to achieve high efficiency due to turbine efficiency being correlated with the tip clearance as a percentage of the annulus height. For these reasons, active turbine tip clearance control (ATTCC) is of interest for future commercial aircraft engines. Such systems will need an actuator to maintain the tip clearance such that the engine achieves good efficiency while maintaining safety margins to prevent blade rubs that could shorten the life of the engine components or lead to an immediate failure in severe cases.

There are various ideas for actuating the turbine tip clearance ranging from well-explored actuation techniques such as hydraulic, pneumatic, and piezoelectric actuator systems to less mature technologies such as smart materials and plasma actuation $[1,7,8,9,10]$. In any case, the actuator will need to be able to maintain a tip clearance that provides enough of a performance benefit to out-weigh its implementation penalties while warranting its added complexity to the engine system. The actuator should also not be over designed such that the complexity and cost to the engine outweigh the benefit of its additional capabilities. Regardless of the type of actuator, they all share generic properties that can be evaluated on a general basis such as bandwidth, rate limits, saturation limits, and deadband.

This paper documents a parametric study of how the variations of generic actuator parameters effect tip clearance. In particular, the study estimates the minimum maintainable tip clearance for a given actuator and evaluates the performance benefit based on performance metrics such as the TSFC and inlet gas path temperature at the cruise condition. Beyond this, weight restrictions and force requirements are discussed. A simplistic actuator model with a Proportional-Integral (PI) controller utilizing wind-up protection logic was used in this study. The actuator model was integrated with a tip clearance model that has been added to the Commercial Modular AeroPropulsion System Simulation 40k (C-MAPSS40k) engine model [11]. This model is representative of a modern twin spool high bypass engine in the $40,000 \mathrm{lb}_{\mathrm{f}}$ thrust class. Therefore, the results of this study are applicable to modern turbofan engines. This study should provide a basis for investigating actuator requirements for such futuristic engines.

This paper is organized as follows. First, the tip clearance model utilized in this study is overviewed. Then the actuator modeling and controller design is addressed. This leads into the simulation portion of the paper in which the simulation scenario is described and results are discussed. Finally, there are some concluding remarks. 


\section{NOMENCLATURE}

a

ATTCC

$B W$

C-MAPSS40k

$C_{p}$

$D B$

FDM

$h$

$h_{\text {coeff }}$

HPS

HPT

IWP

$K_{p}$

$K_{i}$

$k$

L

$L_{b}$

Lo

LPT

$\dot{m}$

$\dot{m}_{\text {des }}$

$n$

PI

PID

PLA

$R$

$r_{\text {rout }}$

$r_{s, i n}$

$R L$

$S L$

$T$

$T_{4}$

$T_{\text {des }}$

$T_{\infty}$

$t$

$T C$

TSFC

V

W

$w_{f}$

X

$x$

ZOH

Greek

$\alpha$

$\delta$

$\Delta$

$\eta$

$\rho$ shape coefficient

Active Turbine Tip Clearance Control

bandwidth

Commercial Modular Aero-Propulsion System

Simulation $40 \mathrm{k}$

heat capacity

deadband

finite difference method

convective heat transfer coefficient

coefficient in convective heat transfer coefficient model

high pressure spool

high pressure turbine

integral wind-up protection

proportional control gain

Integral control gain

thermal conductivity

generic length

length of the blade

known length of a component at temperature $T_{0}$

low pressure turbine

mass flow rate

design mass flow rate for the convective heat

transfer model, $h=h_{\text {coeff }}\left(T / T_{\text {des }}\right)^{0.23}\left(\dot{m} / \dot{m}_{\text {des }}\right)^{0.8}$,

when $h=h_{\text {coeff }}$ and $T=T_{\text {des }}$.

number of engines used on a given aircraft

proportional integral

proportional integral derivative

power lever angle (throttle command)

tip clearance reference $\&$ flight range

outer radius of the rotor

inner radius of the shroud

rate limit

saturation limit

temperature

turbine inlet temperature

design fluid temperature for the convective heat transfer model, $h=h_{\text {coeff }}\left(T / T_{\text {des }}\right)^{0.23}\left(\dot{m} / \dot{m}_{\text {des }}\right)^{0.8}$,

when $h=h_{\text {coeff }}$ and $\dot{m}=\dot{m}_{\text {des }}$.

temperature of the fluid in contact with the surface node

time

tip clearance

thrust specific fuel consumption

air speed

weight

fuel flow rate

actuator position

spatial variable

zero-order hold

thermal expansion coefficient

distance between nodes

difference/change

turbine efficiency

density standard deviation

Subscripts
A/C
act
base
cmd
fb
fuel
inside
j
reserve
sens
surf
w/ act

aircraft with passengers and luggage

actual value

nominal/baseline value (no active control)

controller command

feedback value

fuel parameter value

property of the interior node neighboring a surface

node

spatial/node index

fuel reserve

sensed value

property of a surface node

property associated with having a tip clearance

control actuator

\section{TIP CLEARANCE MODEL OVERVIEW}

The tip clearance model utilized in this study is a modified version of the model described in Ref. [12] that itself is based on the work documented in Ref. [2], [13], and [14]. For the sake of completeness, the model will be summarized at a high level with the modifications described in more detail.

The model considers axisymmetric variations in the tip clearance. Specifically, this refers to deformations in the turbine structure due to centrifugal force, and axisymmetric temperature variations. Asymmetric deformations, such as those due to non-uniform heating and non-uniform aerodynamic loads, are not considered in this model. Since most of the tip clearance deformation is attributed to axisymmetric deformations and the important dynamics of the tip clearance transient have been demonstrated, this model is seen to be appropriate for this study.

The tip clearance model requires an estimation of the deformation in three basic components of the engine; the shroud, rotor, and blade. The shroud is the containment structure on the outside of the HPT flow path. It is assumed to consist of an outer structural layer and an inner abradable layer that acts as a thermal barrier. The rotor is the structural member that connects the blade to the shaft. The blade is the structural member that extends from the rotor into the HPT gas path that extracts work from the flow. The tip clearance is simply derived from geometry as can be seen in Fig. 1 and is given by Eq. (1).

$$
T C=r_{s, \text { in }}-\left(r_{r, \text { out }}+L_{b}\right)
$$

In Eq. (1) $T C$ is the tip clearance, $r_{s, i n}$ is the radius of the inner surface of the shroud, $r_{r \text { out }}$ is the outer radius of the rotor, and $L_{b}$ is the length of the blade. Each of these terms is a function of temperature and where appropriate shaft speed. For the purposes of the model, the shank depicted in Fig. 1 that connects the blade to the rotor is treated as an extension of the rotor. 


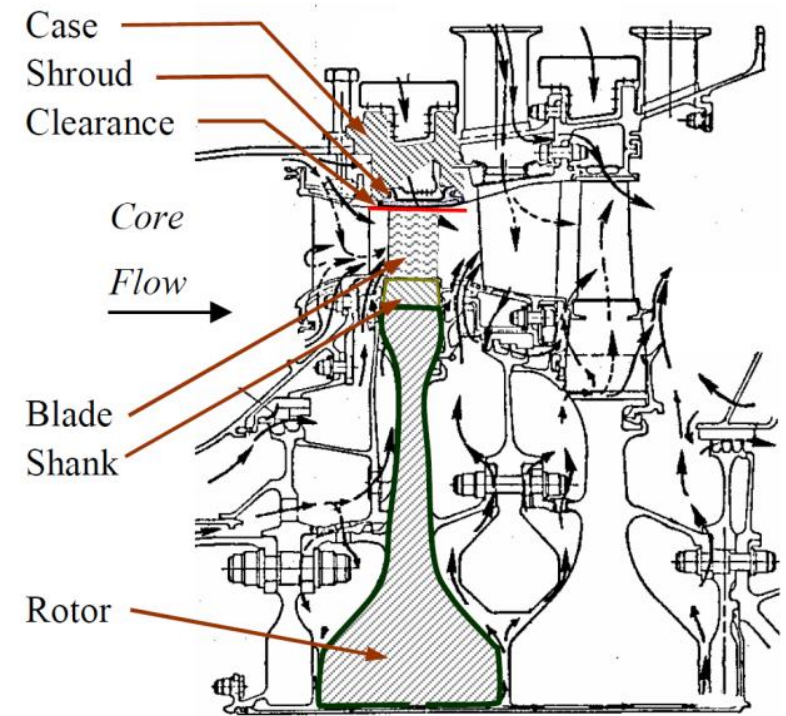

Figure 1. Schematic of the HPT and surrounding structure [2]

The methods for determining the thermal expansion of each of the modeled components has been updated to account for temperature dependent properties based on work presented in Ref. [15]. The more general form of the 1-D heat equation shown in Eq. (2) was solved for both the rotor and the shroud.

$$
\frac{\partial T}{\partial t}=\frac{1}{\rho C_{p}}\left[\left(\frac{\partial k}{\partial x}+\frac{a k}{x}\right) \frac{\partial T}{\partial x}+k \frac{\partial^{2} T}{\partial x^{2}}\right]
$$

Here $T$ is the temperature solution, $t$ is the time, $x$ is the spatial variable, $k$ is the thermal conductivity, $C_{p}$ is the heat capacity, and $\rho$ is the density. Eq. (2) is applicable to planar geometries when $a=0$ and applicable to cylindrical geometries when $a=$ 1. Recall from Ref. [12] that the rotor is modeled with a 1-D approach across the rotor disc's width due to the dominance of convective heat transfer from cooling flows on its front and back surfaces. Therefore, a planar geometry assumption is most appropriate. The shroud resembles a hollow cylindrical shell and so a cylindrical geometry is most appropriate in this instance.

From Ref. [15], Eq. (2) was solved using a finite difference method (FDM) approach via the Crank-Nicolson method described in Ref. [16]. A general non-uniform spatial discretization was considered [15]. Eq. (2) was discretized according to Ref. [15] and solved using Thomas's Algorithm [16]. Although the discretization contains terms that are capable of considering changes in material properties, a large abrupt change in thermal properties due to a transition in materials can lead to inaccuracy in results, particularly in the estimation of the derivative of thermal conductivity with respect to the spatial variable. Therefore, the method from Ref. [12] was applied for handling material transitions in the shroud but thermal property variations within the same material are handled using the discretized equations from Ref. [15].

The boundary conditions were enforced through the boundary node equations, which address convection and neglect radiation. The boundary nodes were assumed to be half the thickness of their neighboring interior node. Eq. (3) and (4) below provide the boundary node equations for planar and cylindrical geometries respectively.

$$
\begin{aligned}
& \rho C_{p} \frac{\Delta x}{2} \frac{\partial T_{\text {surf }}}{\partial t}=\frac{k}{\Delta x}\left(T_{\text {inside }}-T_{\text {surf }}\right)+h\left(T_{\infty}-T_{\text {surf }}\right) \\
& \rho C_{p}\left(x_{\text {out } 2}^{2}-x_{\text {in } 2}^{2}\right) \frac{\partial T_{\text {surf }}}{\partial t}=\frac{2 k}{\ln \left(x_{\text {out } 1} / x_{\text {in } 1}\right)}\left(T_{\text {inside }}-T_{\text {surf }}\right) \ldots \\
+ & 2 h x_{\text {surf }}\left(T_{\infty}-T_{\text {surf }}\right)
\end{aligned}
$$

In Eq. (3), $\Delta x$ is the node thickness of the neighboring interior node. In both equations, $T_{\text {sur }}$ is the temperature of the surface node, $T_{\text {inside }}$ is the temperature of the neighboring interior node, $T_{\infty}$ is the temperature of the fluid in contact with the surface node, and $h$ is the convective heat transfer coefficient. The values of $x_{\text {in } 1}, x_{\text {out } 1}, x_{i n 2}$, and $x_{\text {out } 2}$ in Eq. (4) are dependent on whether the given surface node is the inner or outer surface node.

Inner surface node:

$\begin{array}{ll}x_{\text {in } 1}=x_{\text {surf }} & x_{\text {in } 2}=x_{\text {surf }} \\ x_{\text {out } 1}=x_{\text {inside }} & x_{\text {out } 2}=x_{\text {inside }}-\Delta x / 2\end{array}$

Outer surface node:

$$
\begin{array}{ll}
x_{\text {in } 1}=x_{\text {inside }} & x_{\text {in } 2}=x_{\text {inside }}+\Delta x / 2 \\
x_{\text {out } 1}=x_{\text {surf }} & x_{\text {out } 2}=x_{\text {surf }}
\end{array}
$$

As discussed in Ref. [15], Eq. (3) and (4) can be discretized in a similar manner as Eq. (2) and included in the system of equations with the interior nodes, which is solved simultaneously to obtain the temperature solution.

Ref. [12] assumes the convective heat transfer coefficient is constant. In reality, the convective heat transfer coefficients in the gas path and cooling flow paths will vary though the course of a flight. It is expected to be a strong function of mass flow rate and could be significantly impacted by the gas temperature. In particular, one would expect the convective heat transfer to be strengthened at low altitude and high power settings while it will be weaker at high altitude and low power setting conditions. The tip clearance model has been updated to allow the convective heat transfer coefficient to be interpolated based on data or computed using the following expression leveraged from Ref. [17]. 


$$
h=h_{\text {coeff }}\left(\frac{T}{T_{d e s}}\right)^{0.23}\left(\frac{\dot{m}}{\dot{m}_{\text {des }}}\right)^{0.8}
$$

This general empirical model was used where $T$ and $\dot{m}$ are the current temperature and mass flow rate of the fluid, and $T_{\text {des }}$ and $\dot{m}_{d e s}$ are the temperature and mass flow rate at some known data point where $h=h_{\text {coeff }}$.

The updated approach for determining the thermal deformation of each component uses the average temperature of each respective component as was done in Ref. [12] but it differs by accounting for temperature-dependent thermal expansion coefficients using the following fundamental equation.

$$
L=L_{0}\left[1+\int_{T_{0}}^{T} \alpha(T) d T\right]
$$

In Eq. (6) $L$ is a generic length for the component of interest, $L_{0}$ is the length of the component at temperature $T_{0}, T$ is the current temperature, and $\alpha$ is the thermal expansion coefficient. Unlike the previous approach, this model accounts for expansion of the abradable layer of the shroud, which is subtracted from the inner structural layer radius to obtain $r_{s, i n}$.

In a similar manner, temperature dependence of mechanical properties such as Young's Modulus and Poisson's Ratio were considered. The expressions for centrifugal deformation provided in Ref. [12] are general enough to be applicable to temperature dependent mechanical properties and therefore no changes were required other than interpolating the mechanical properties each time-step of the simulation based on the current average temperature of the given component.

The components were assumed to be made of the same materials as they were in Ref. [12]. The rotor, blade, and structural layer of the shroud were all assumed to be made of a material similar to Inconel 718 while the abradable material of the shroud was assumed to be Zirconium Oxide. The size of the components were inferred based on best engineering guesses and measurements for engines in the same thrust-class as C-MAPSS40k which is a $40,000 \mathrm{lb}_{\mathrm{f}}$ thrust engine [18].

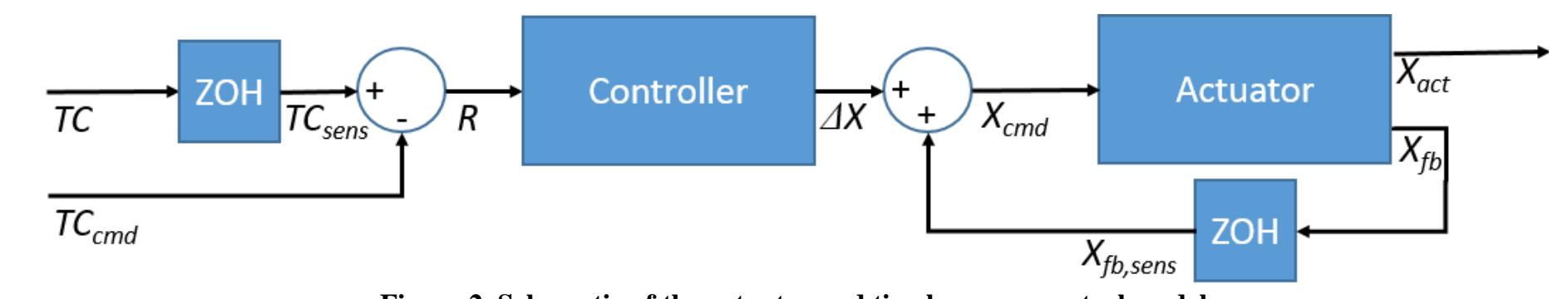

Figure 2. Schematic of the actuator and tip clearance control model

\section{ACTUATOR AND CONTROLLER MODELING}

In this study, the tip clearance is assumed to be sensed and the actuator movement is described in terms of displacement from the nominal containment structure position (without active control). In reality, the actuator may exist in a different form and have a different range of movement. However, in the end the effect is essentially the same. The actuator was modeled using a generic first order transfer function with a specified bandwidth $(B W)$. Non-linear dynamics were added through enforcement of saturation limits $(S L)$, rate limits $(R L)$, and deadband $(D B)$. The saturation limit and rate limit were applied to the actual actuator position response $X_{a c t}$ while the deadband was applied to the feedback position $X_{f b}$.

The actuator was assumed to be connected or otherwise incorporated with the containment structure; therefore, the actuator position is defined relative to the inner circumference of the containment structure with the positive direction pointing inward toward the turbine blade. The tip clearance and actuator position feedback sensors were assumed to be perfect in the sense that they react instantaneously upon being sampled and provide the exact value of the sensed variable. The sensors signals were constructed using a zero-order hold $(\mathrm{ZOH})$ model. The reference signal $R$ to the controller was the difference between the sensed tip clearance $T C_{\text {sens }}$ and the command $T C_{c m d}$. The change in actuator position $\Delta X$ was computed using a Proportional Integral (PI) controller. The commanded actuator local loop closure position $X_{\text {cmd }}$ was the sum of the sensed feedback position of the actuator $X_{f b, s e n s}$ and $\Delta X$. Figure 2 provides a schematic of the described model.

The controllers used in this study were designed using the MATLAB $^{\circledR}$ Control Systems Toolbox's (version 9.9) pidtune function. To promote a level playing field for all of the actuators in the study, each actuator implemented a PI control logic with a proportional control gain $K_{p}$ and integral control gain $K_{i}$ determined using the same tuning algorithm. For each actuator the phase margin was set to $90^{\circ}$ to encourage a robust design with a conservative response time. The step response of the closed loop system was designed to be critically damped. The control design was evaluated for a spectrum of cross-over frequencies and the controller design that produced the fastest settling time with no overshoot was selected for use in the simulation. Limiting overshoot was seen as advantageous to this application where excessive overshoot could result in a blade rub event. Minimizing the settling time was seen as a way to put all of the actuators on the same playing field while also 


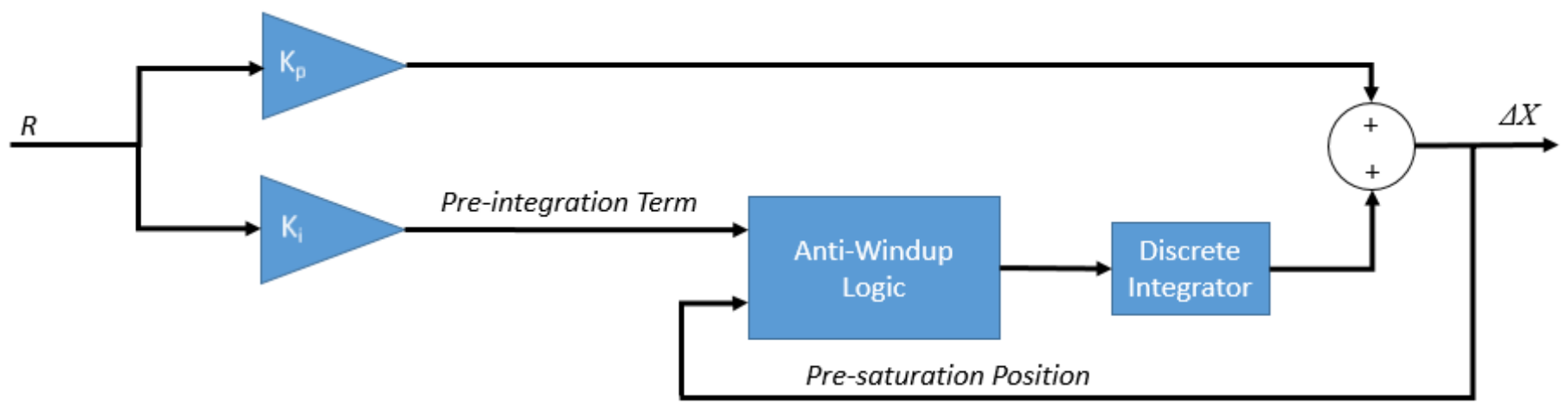

Figure 3. Tip clearance control logic

promoting the performance of the system, which could be valuable in assessing the potential benefits of active tip clearance control. A schematic of the control logic is provided in Fig. 3.

A clamping circuit was integrated with the controller for integral windup protection, mainly against actuator saturation. The clamping circuit works by stopping integration when the actuator is saturated. Specifically the input to the discrete-time integrator is set to zero when the pre-saturated position command is outside of the saturation limits and the preintegrator term and pre-saturation command have the same sign (i.e. when the actuator is saturated and the controller is going to command the actuator further into saturation).

\section{SIMULATION}

This section describes the simulation scenario that was applied to access the actuator requirement and it also presents and discusses the results.

\section{Minimum Clearance Margin \& Baseline Clearance}

Ref. [19] evaluated the HPT tip clearance for the JT9D engine for various scenarios including takeoff/climb, in-flight restart, thrust reversal, a hard turn, and aircraft stall. Axisymmetric and asymmetric deformations were considered. The JT9D engine is similar in size and thrust to the class of engine that is represented by C-MAPSS40k and therefore the information in the study was used to verify realistic behavior of the tip clearance model. The largest axisymmetric closure change was observed for an in-flight restart and was $\sim 39$ mils while for the more common scenario of a takeoff/climb the axisymmetric deformation was $\sim 31$ mils. Asymmetric and flight load closures during these scenarios increased the total closure change to $\sim 42 \mathrm{mils}$ and $\sim 46 \mathrm{mils}$ respectively. Though the inflight restart scenario could produce more severe axisymmetric deformations, it was not considered as the worst case for this study. The reason for this is that if the engine has to be restarted during flight then efficiency is not the biggest concern, especially seeing that the engine is not using fuel or producing thrust to begin with. Therefore, in this scenario it seems reasonable to build control logic into the actuator control loop to open up the tip clearance gap as much as possible and resume active control shortly after the engine restarts. With this assumption, the worst-case condition seems to be the takeoff/climb scenario or an in-flight deceleration and reacceleration as suggested by Ref. [1] and [19].

Given that the model only accounts for axisymmetric tip clearance variations, it was assumed that the actuator would seek to address axisymmetric tip clearance variations as much as possible while maintaining a clearance margin to address asymmetric tip clearance variations. From Ref. [19], the asymmetric tip clearance variation was recorded to be as much as 15 mils. An additional 5 mils was added to address unaccounted for factors such as sensor bias, control system delays, and additional uncertainties. The goal then was to find the minimum maintainable tip clearance for each actuator considered in the study and its associated performance such that 20mils of tip clearance was maintained during all transients. This was done iteratively by adjusting the regulated tip clearance.

Seeing as the maximum anticipated axisymmetric change in tip clearance is expected to be $\sim 30$ mils and a $20 \mathrm{mil}$ clearance should be carried at minimum due to asymmetric changes in tip clearance, the tip clearance at ground idle was set to be 55mils. The additional 5 mils in this case is attributed to conservativeness in the current design based on the inability to actively measure and control the tip clearance. Note that the assumption is that the baseline tip clearance is directly related to the potential benefits that could be extracted with active turbine tip clearance control. If the baseline tip clearance were to be larger, then the potential performance benefits could be even higher then what is presented in this paper.

\section{Simulation Scenario}

The flight scenario consists of several segments and includes take-off, climb, cruise, an acceleration to full-power from cruise, a deceleration to idle at altitude followed by an acceleration back to full power, descent, and a go-around upon a landing attempt. The flight profile is plotted in Fig. 4. PLA refers to the power lever angle, which is the pilot's throttle command to the engine controller. On the plotted scale, $40^{\circ}$ corresponds to idle and $80^{\circ}$ corresponds to full-power. Note 

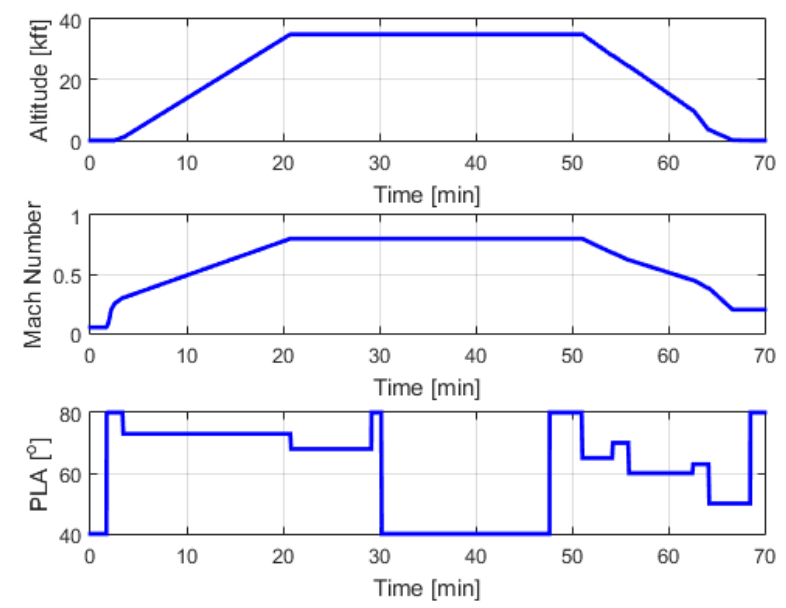

Figure 4. Simulation flight profile

that the portion of flight between 30 and $47.5 \mathrm{~min}$ is not typical of a commercial flight profile. This portion of flight was added for the purpose of evaluating the potential worst case scenario of a deceleration to idle followed by an abrupt acceleration to full-power after the engine has been provided time to cool down. The maneuver does not consider changes in Mach number or altitude that may result from the decrease in engine thrust but instead assumes other engines and or flight controls are used to maintain altitude and speed.

To provide a means of comparison, a baseline simulation was conducted to determine the tip clearance response and engine performance when no fast response actuation is implemented. The results of this simulation are provided in Fig. 5 and 6 . The performance during steady-state cruise is of the most interest. The cruise segment of the flight profile in Fig. 4 spans from $\sim 21-29 \mathrm{~min}$ but a slow transient persists through most of this time as a result of thermal expansion that shifts the operating point of the engine until all components have reached their steady-state temperature. Steady-state cruise is considered to be reached when all transients, including the thermal transients have ceased. This state was reached by the end of the cruise segment ( 29min). Since the engine will spend most of its time at this operating point, the tip clearance and performance parameters were extracted from this data point and used in evaluating the benefit of each actuator. Each actuator was compared against the baseline quantities provided in Table 1 . Note that $T_{4}$ is the turbine inlet temperature, $\eta$ is the turbine efficiency, $w_{f}$ is the fuel flow rate, and TSFC is the thrust specific fuel consumption.

Table 1. Baseline performance metrics at cruise

\begin{tabular}{ll}
\hline \hline Variable & Value \\
\hline Tip Clearance, $T C$ & $50.31 \mathrm{mils}$ \\
Turbine Efficiency, $\eta$ & 0.8922 \\
Fuel Flow Rate, $w_{f}$ & $1.4011 \mathrm{~b}_{\mathrm{m}} / \mathrm{sec}$ \\
Thrust Specific Fuel Consumption, $T S F C$ & 0.2428 \\
Turbine Inlet Temperature, $T_{4}$ & $2840^{\circ} \mathrm{R}$ \\
\hline \hline
\end{tabular}
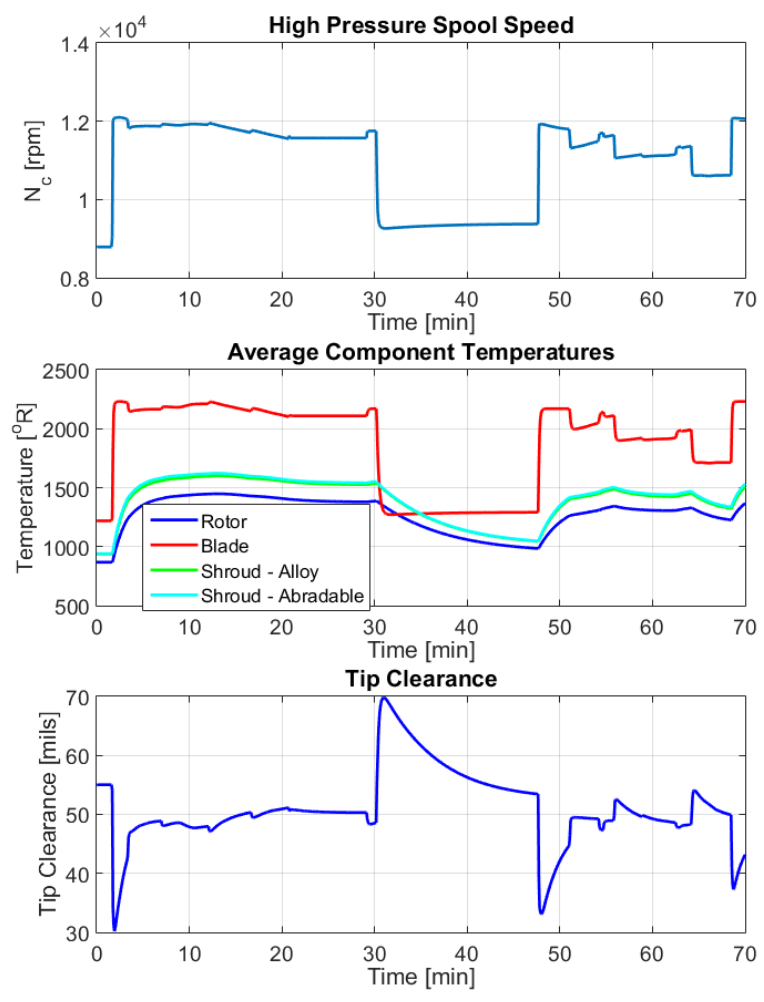

Figure 5. Baseline response
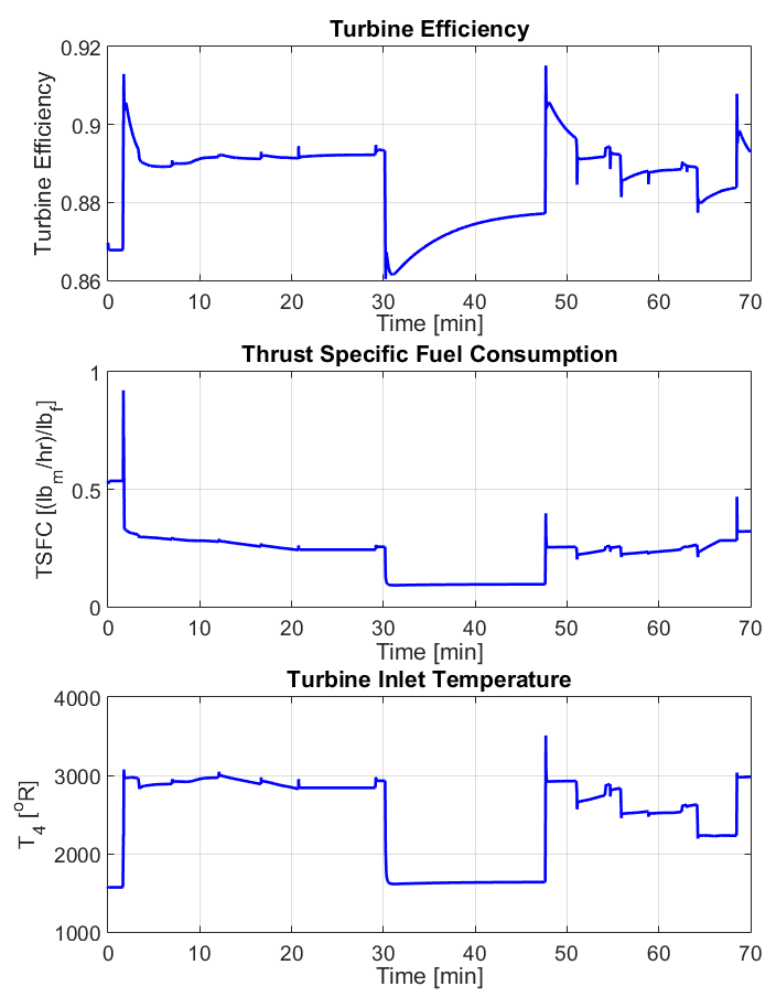

Figure 6. Baseline performance metrics 


\section{Evaluation of Basic Actuator Parameters}

Various actuator parameters were evaluated through the course of this study. First, bandwidth was considered alone to establish the appropriate range of actuator speed. Once this was established, several bandwidth and rate limit combinations were considered. Based on results from these studies, actuator position responses were used to infer appropriate actuator range requirements. The next several paragraphs discuss the results of these studies.

The range of appropriate bandwidths was determined by varying the bandwidth of the actuator through several simulations of the previously defined flight profile while enforcing no saturation limits or rate limits and assuming the deadband to be zero. The results of these simulations are summarized in Fig. 7, which plots the tip clearance and performance parameters at the cruise point for various amounts of actuator bandwidth. Recall that the tip clearance at cruise is constrained by transients experienced during the rest of the
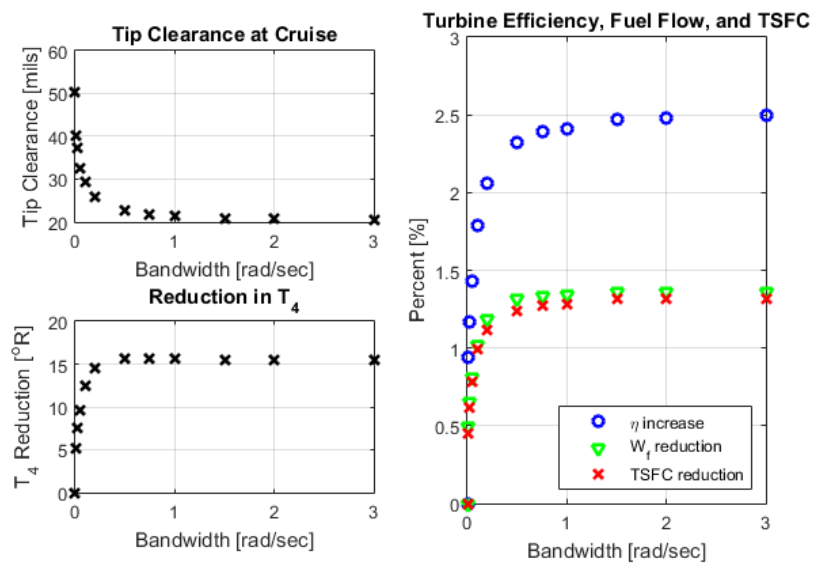

Figure 7. Tip clearance and performance metrics at cruise for actuators with various bandwidths
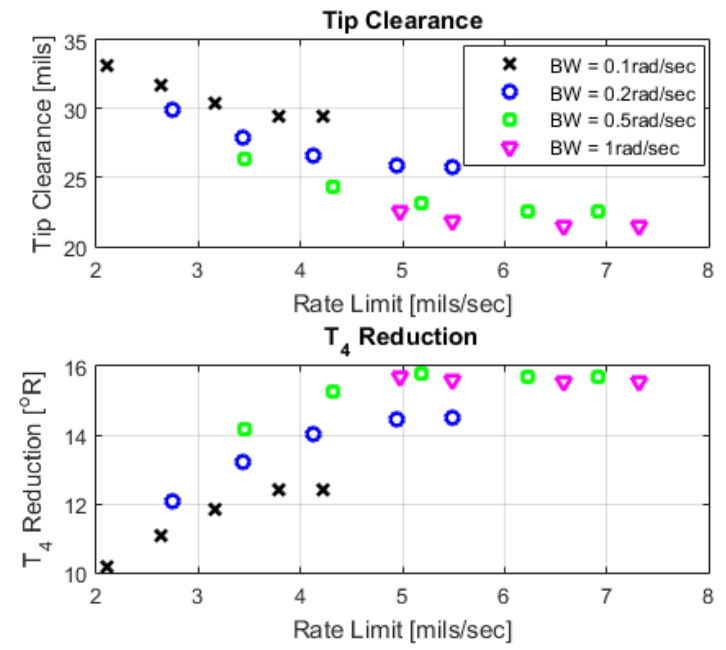

flight such that acceptable margins are maintained. Specifically the minimum tip clearance throughout the flight should be close to but no less than 20mils. Observation of these results led to an appropriate bandwidth range being identified as $0.1-1 \mathrm{rad} / \mathrm{sec}$. This is inferred based on the observation that there is a steep fall-off in performance benefits for a bandwidth below $0.1 \mathrm{rad} / \mathrm{sec}$ and little reward for increasing the bandwidth beyond $1 \mathrm{rad} / \mathrm{sec}$.

Next a set of simulations were performed to evaluate the impact of rate limit contraints. Each simulation enforced rate limits that were a percentage of the maximum actuation rate. For actuator bandwidths of $0.1,0.2$, and $0.5 \mathrm{rad} / \mathrm{sec}$ these rate limits were $100 \%, 90 \%, 75 \%, 62.5 \%$, and $50 \%$ of the maximum actuation rate. In the case where the actuator bandwidth was $1 \mathrm{rad} / \mathrm{sec}$, the rate limit range was restricted to $100 \%, 90 \%, 75 \%$, and $68 \%$. The reason for this was controller induced performance degradation at lower rate limits, which was attributed to wind-up in the integral term of the control logic. Recall that the control law was developed based on the linear system that considers the bandwidth but not the rate limit. Due to the actuator not responding as fast as the controller expects, error accumulates in the integral term during the transients, which can lead to delays in the actuator response, unanticipated overshoot, and oscillations that could produce results that do not follow the expected trends.

Results for the tested combinations of bandwidth and rate limit are summarized in Fig. 8. The relevant range of bandwidth and rate limits for fast response turbine tip clearance control could be determined by considering Fig. 9, which relates each combination to its reduction in TSFC. Note that it is possible that actuators in the unconsidered region, characterized by high bandwidth and relatively low rate limit, could be applicable if the controller was redesigned. Due to the nature of this problem, it may require alterations to be made to the control algorithm. This is not ideal for evaluating the
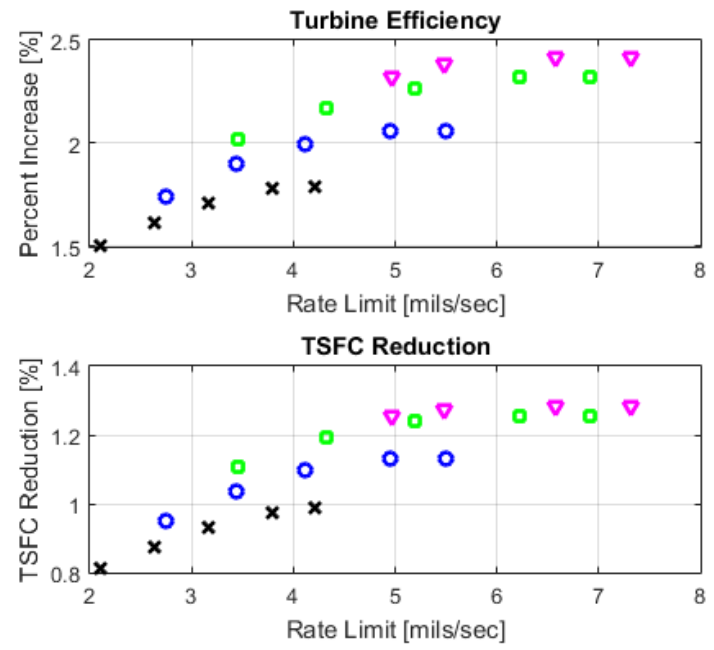

Figure 8. Tip clearance and performance metrics at cruise for actuators with various combination of bandwidth and rate limit 


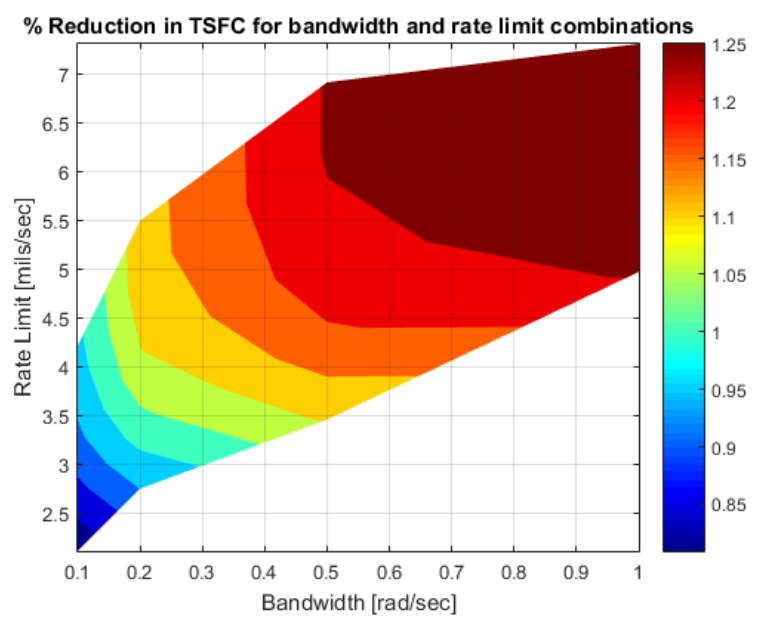

Figure 9. Cruise TSFC as a function of actuator bandwidth and rate limit

actuators on a consistent basis and therefore actuators in this region are not considered in this study.

Based on the observed range of actuator movement during the simulation, some saturation limit requirements are suggested. Two scenarios are considered. In the first, it is desired to regulate the tip clearance during all maneuvers including those that open the clearance such as decelerations, whereas the second only considers regulating tip clearance during steady state operation and transients that reduce the tip clearance. In the latter case, the control logic or physical actuator limits could prevent the actuator from moving beyond a given position. Based on the results of the bandwidth study, as summarized in Fig. 10, it appears that the actuator position ranges from $\sim-8$ mils to $\sim 48$ mils. For any given actuator bandwidth the overall range of movement was $\sim 36 \mathrm{mils}$ to $\sim 42$ mils. For the bandwidth range of interest, it seems reasonable to suggest that an actuator range of $\sim 40 \mathrm{mils}$ is appropriate for this application. If the actuator transient during

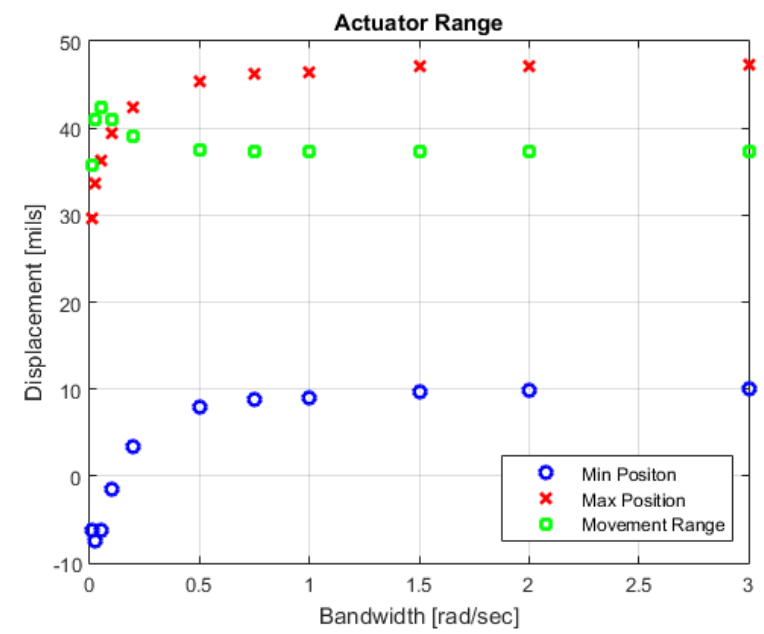

Figure 10. Actuator range from the bandwidth study the deceleration, as indicated in Fig. 11, were to be ignored then theoretically the actuator range could be reduced to $\sim 35$ mils with the current containment structure or even to $\sim 30$ mils if the radius of the containment structure were to be decreased. Based on these observations the actuator ranges seem to be very reasonable. Given that there is a steep fall-off in the benefit to engine performance for tip clearances larger than what is maintained here, limiting the movement range any further may not be worth the investment in implementing active clearance control. This also leads into the concern of integral wind-up for saturated tip clearance control actuators that would be exacerbated by the smaller saturation limits.

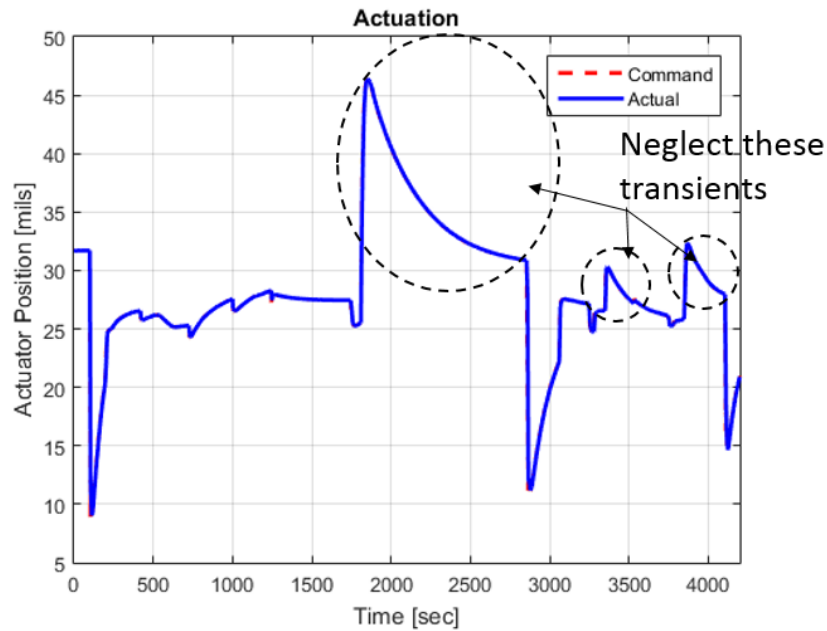

Figure 11. Actuator position $(B W=1 \mathrm{rad} / \mathrm{sec})$ with the circled regions identifying transients that could be ignored

\section{Weight and Force Considerations}

Weight restrictions for the tip clearance actuation system could be evaluated in several ways. A starting point was to look at the weight of the fuel saved through use of an actuator to control the tip clearance. Figure 12 uses fuel flow rate data from the simulations to provide an idea of the fuel savings as a function of cruise time. The top plot in Fig. 12 indicates the fuel saving for a single engine. The C-MAPSS40k engine may be applicable to a 2-engine narrow-body jet or a 4-engine widebody jet. Note that modern wide body aircraft are converging toward a 2-engine configuration. However, given the thrust class of the C-MAPSS40k engine, a 2-engine configuration would not be appropriate, hence the 4-engine configuration. The estimated total fuel savings for both of these types of aircraft are shown in Fig. 12. The bottom plots in Fig. 12 indicate the total fuel saved for the 2-engine narrow body and 4-engine wide body configurations. The average and one standard deviation $(1 \sigma)$ lines were derived from data extracted for numerous flights occurring on September 19, 2016 and September 20, 2016, available from Ref. [20] for Boeing 737800 flights and Boeing 777-300ER flights respectively. 

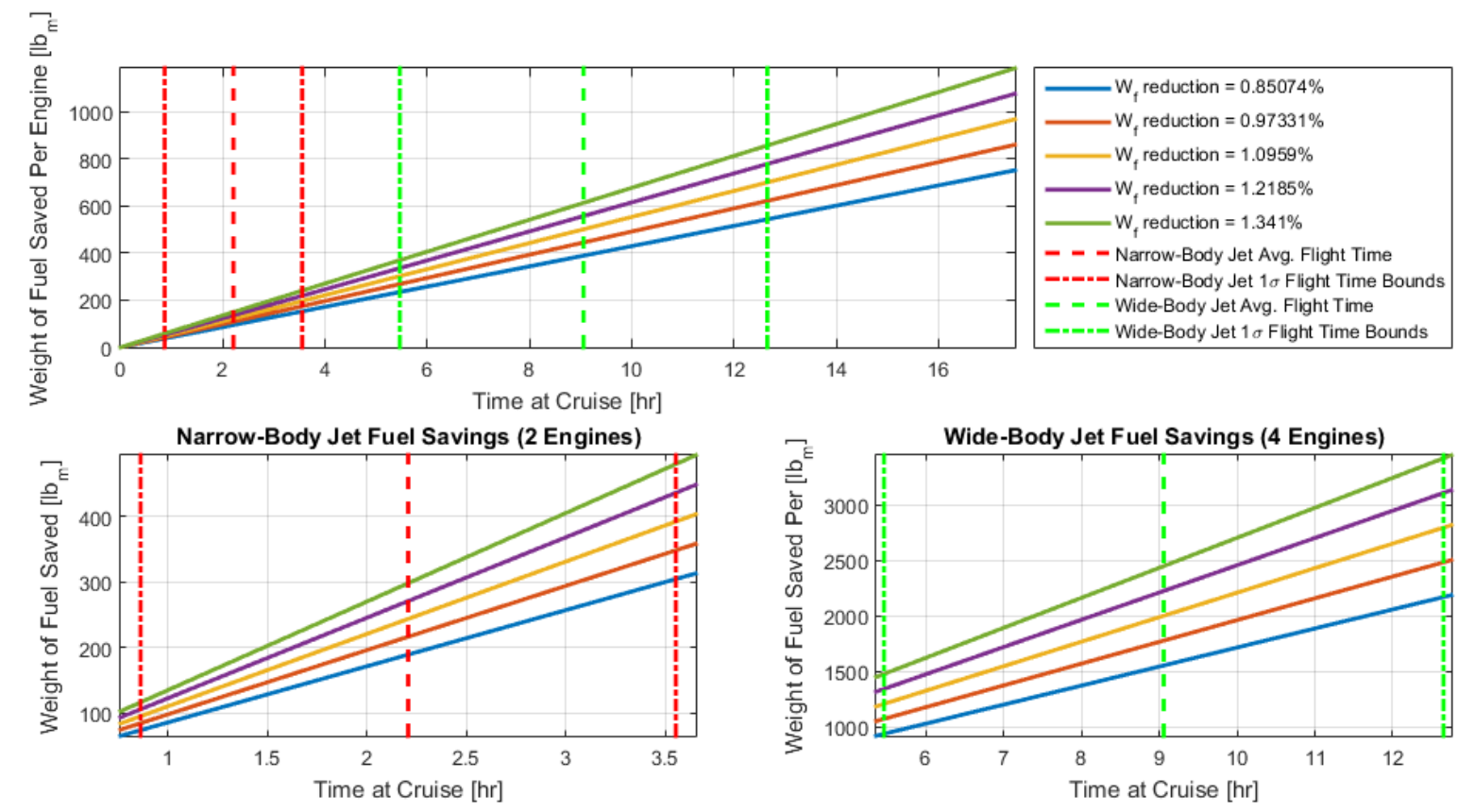

Figure 12. Potential weight saving as a result of carrying less fuel

The information in Fig. 12 could be used to evaluate trades when considering the financial saving of using less fuel. However, the constraint on the weight of the actuation system is not as simple as considering it to be the weight of the fuel saved. A more appropriate assessment of the actuator weight restriction is to determine the weight that can be added to an aircraft while still achieving the same range and carrying the same payload. This is because range and payload are constant parameters for commercial flights and the real goal is to get the payload to the destination using less fuel. Using the Breguet range equation [21], the maximum weight of the tip clearance actuation system, $W_{a c t}$, can be evaluated by solving the equation below:

$$
\begin{aligned}
& \frac{1}{T S F C_{\text {w/act }}} \ln \left(\frac{W_{A / C}+W_{\text {reserve, } w / a c t}+W_{\text {fuel }, w / a c t}+W_{\text {act }} / n}{W_{A / C}+W_{\text {reserve, } w / a c t}+W_{\text {act }} / n}\right) \\
& -\frac{1}{T S F C_{\text {base }}} \ln \left(\frac{W_{A / C}+W_{\text {reserve,base }}+W_{\text {fuel,base }}}{W_{A / C}+W_{\text {reserve,base }}}\right)=0
\end{aligned}
$$

where

$$
\begin{aligned}
W_{\text {reserve,base }} & =n w_{f, \text { base }} t_{\text {reserve }} \\
W_{\text {fuel,base }} & =n w_{f, \text { base }} \frac{R}{V} \\
W_{\text {reserve,w/act }} & =n w_{f, w / a c t} t_{\text {reserve }} \\
W_{\text {fuel,w/act }} & =n w_{f, w / a c t} \frac{R}{V}
\end{aligned}
$$

$W_{A / C}$ is the weight of the aircraft with passengers and luggage, and $W_{\text {reserve }}$ is the weight of the fuel that is carried in reserve in the case of an emergency. Ref. [22] indicates that the FAA requires domestic airlines carry enough fuel to continue to an alternate airport, plus an additional 45min after. Furthermore, the alternate airport must have a good weather forecast. Ref. [22] continues to suggest that on average an extra 70min of additional fuel is carried in reserve. The parameter $t_{\text {reserve }}$ refers to this flight time in which the reserve fuel is capable of extending the flight. $W_{\text {fuel }}$ is the weight of the fuel used during the flight, $n$ is the number of engines used by the aircraft, $R$ is the range or distance between airports, and $V$ is the average air speed, which is taken to be the cruise speed since that is where the aircraft will likely spend the majority of its time. Most commercial aircraft cruise around the same Mach number and altitude, which are $\sim 0.8$ and $35,000 \mathrm{ft}$, respectively. Using standard atmosphere tables, the ambient temperature and subsequently the speed of sound at this altitude was determined, thus allowing for determination of the cruise speed. The subscript "base" refers to the baseline value that corresponds to the use of no fast response actuator. The subscript " $w / a c t$ " refers to the value corresponding to use of a fast response actuator.

Eq. (7) was solved for various ranges using results from various actuators in the study that have displayed different levels of TSFC and fuel flow rate at cruise. This analysis was done for a narrow-body jet application and a wide-body jet application. Similar to the fuel savings study, the narrow-body jet configuration was assumed to use 2 engines while the widebody jet was assumed to use 4 engines based on the thrust needs of aircraft in these classes. The aircraft weights were based off the empty weight and passenger occupancy limits for 

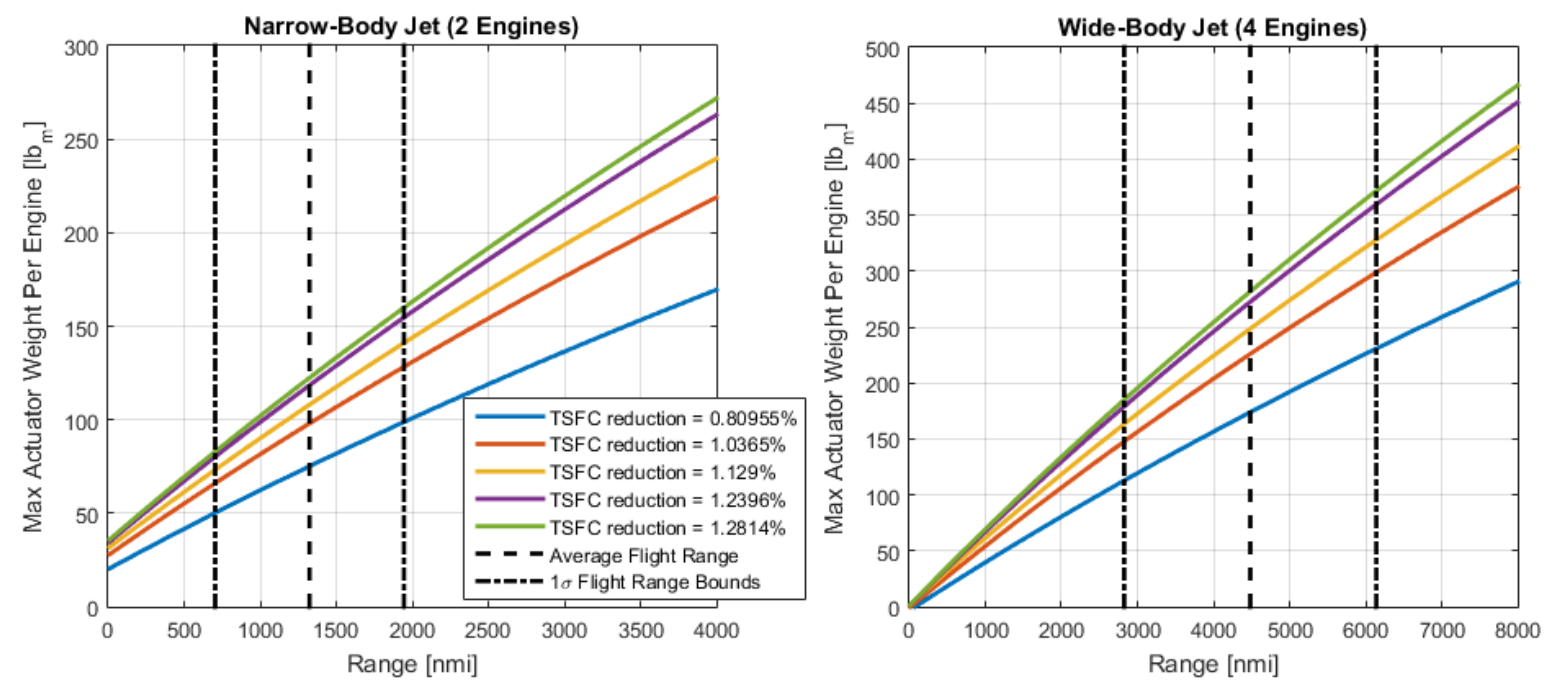

Figure 13. Maximum actuator weight estimations based on the need to fly the same range and carry the same payload

the Boeing 737-800 aircraft and the Boeing 777-300ER aircraft. This information was taken from Ref. [23] and [24] and assumes that each passenger on average weighs $150 \mathrm{lb}$ and has $70 \mathrm{lb}$ of luggage. Figure 13 plots the solutions to Eq. (7) that quantifies the maximum weight that the tip clearance actuation system can add to the engine while still achieving the same range as the baseline engine and carrying the same payload. Figure 13 provides an estimate of the ranges in which narrow-body and wide-body jets typically fly based on data from Ref. [20] that was extracted for flights taking place on the selected dates. This was done to allow one to infer what the expected actuator weight constraint might be for these two classes of aircraft. Note that the presented weight analysis is rough and simplified. Additionally, there may be more factors to consider, some of which are application specific.

Another concern for a tip clearance actuator is the force requirement. Some actuator concepts such as those employing fluidic control and plasma actuation may avoid this consideration but those considering mechanical actuation of any sort, such as hydraulic or pneumatic actuation, will likely have the need to exert some amount of force in-order to maintain the tip clearance position and to change position when needed. Many actuation concepts consider modulation of the shroud, which itself is a pressure vessel. Pressure forces would surely be the dominant force to consider but additional capability may be needed to overcome friction, the weight of the actuator, and inertia forces due to aircraft and engine accelerations and aerodynamic forces applied to them. Furthermore, the actuator would have to exceed the static force requirements in-order to assure the ability to generate enough excess force to accelerate the actuator to an appropriate speed. Obviously, there are many things to consider when evaluating the force requirements for tip clearance actuation systems and the requirement will be dependent on the actuator design. Therefore, the extraction of a general assessment was not sought after. However, some information can be provided in terms of the relevant pressures inside the engine that will likely drive the force requirements for many actuator designs.

The pressure differential that generates the pressure force on the actuation system was investigated on a worst case basis under simplified geometric assumptions. Two scenarios were considered, the first when the actuator surface is to be modulated between the hot gas path and the cooling plenum around the shroud, which is filled with compressor discharge air as depicted in Fig. 14. The second scenario considers the actuator surface moving against a pressure differential created between the hot gas path and the cowl cavity that defines the region of air between the engine casing and the bypass duct. The pressure differentials were calculated based on rules of thumb provided in Ref. [25] and [1]. Fig. 15 plots these pressure differentials for each of the two described scenarios, for the flight profile in Fig. 4. Given the area of the actuation surface the pressure differential could be translated to a force. Therefore, Fig. 15 should give an idea of the range of force that an actuator may have to apply. Furthermore, the bottom plot in

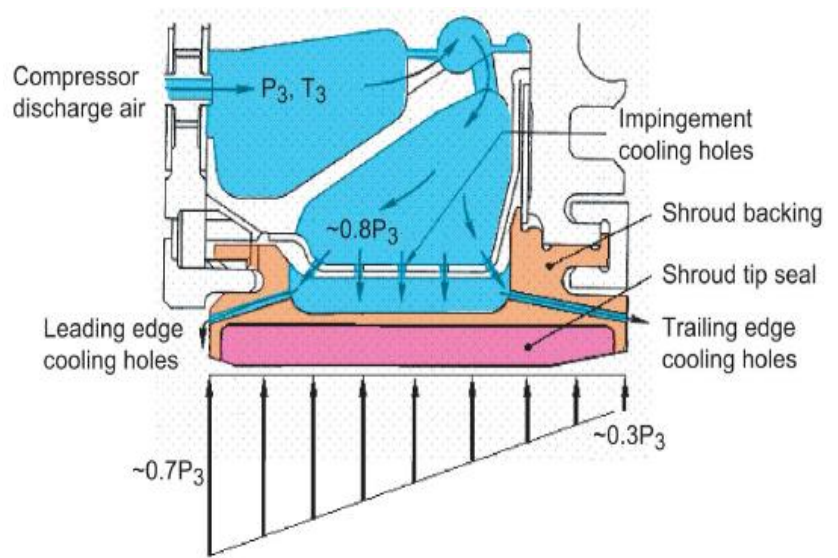

Figure 14. Axial pressure distribution across HPT blade tip seal cross section [25] 
Fig. 15 is a blown up view of the first transient in the top plot. This plot is meant to provide an idea for the required rate of change in applied force for the actuator to maintain its position.
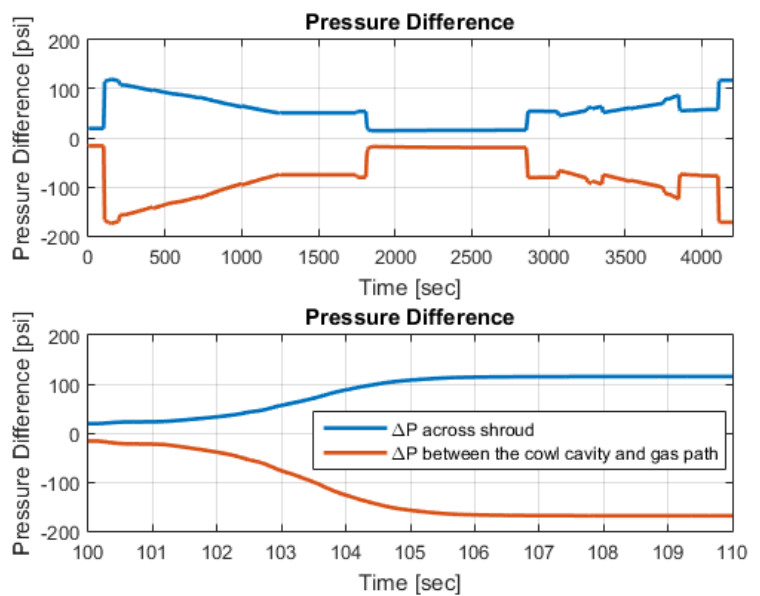

Figure 15. Approximated pressure differential that the tip clearance control actuator will have to work against

\section{Additional Considerations}

There are several additional factors to consider in actuator design and selection as well as the development of control laws. Two such factors that will be discussed here are integral windup for proportional integral derivative (PID) controllers and deadband. Finally, a comprehensive example of a reasonable actuator application is illustrated.

Integral windup refers to the situation where a large change in set-point occurs and the integral term of the control law accumulates significant error during the rise that causes the control input to increase or decrease as the accumulated error is unwound. This can cause excessive overshoot in the system response, which for active tip clearance control could result in a blade rub event. The issue of integral windup is worsened when the control logic is executed but the system does not respond to it. This may occur when an actuator is saturated. While the control logic commands the actuator to move to a position that is outside of its physical capability, error accumulates. When a change in the system occurs, such as a sudden acceleration of the high speed shaft, the integral term must discharge or "un-wind" its excess error before the actuator will become unsaturated and begin to move. This may cause a significant delay in the actuator response. There are integralwindup protection (IWP) techniques that can be used to alleviate this issue but none are perfect. Figure 16 and Fig. 17 shows the impact of integral windup on the actuator position and tip clearance response when the upper saturation limit is set to 20 mils. Figure 16 shows the response when IWP logic is not used and Fig. 17 are the results when the clamping technique described earlier is implemented. It was observed in previous simulations that when no saturation limits were enforced, the
20 mil safety margin was maintained. However, when a saturation limit of +/-20mils was enforced with no IWP logic, the tip clearance reaches a minimum of $\sim 10$ mils. Even with IWP logic the tip clearance reaches a minimum of $\sim 13$ mils. In either case this could have resulted in a blade rub event.

Two factors could play a role in this: (1) the anti-windup technique may not be able to discharge all of the error in time to respond fast enough to the transients, and (2) since the actuator is saturated when the tip clearance transient begins, the tip clearance gap begins to close before the actuator starts to react to the transient (i.e. when the measured tip clearance dips below the regulated tip clearance value). This provides the tip clearance transient with a "running start" before the actuator has an opportunity to react. Because of this, extra safety margins will be needed to address potential saturation scenarios regardless of the integral windup problem.
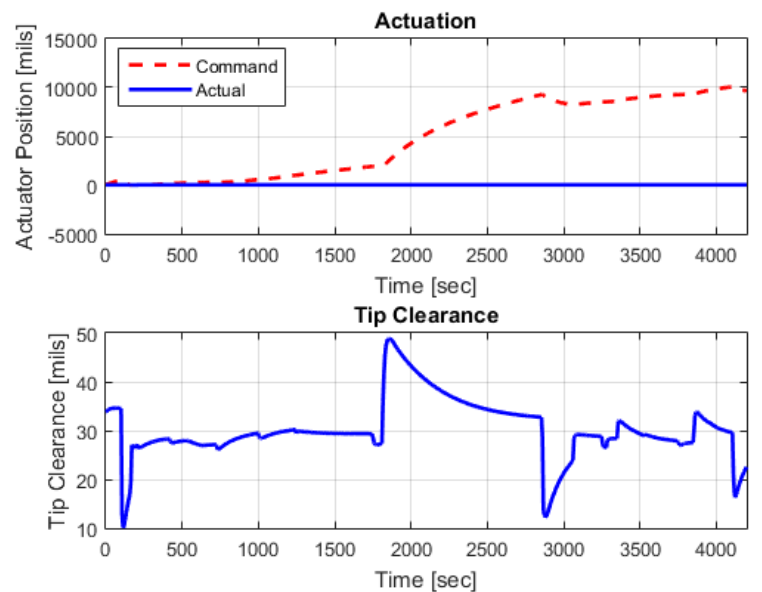

Figure 16. Tip clearance and actuator position response $(B W=0.2 \mathrm{rad} / \mathrm{sec}, R L=4.12 \mathrm{mils} / \mathrm{sec}, S L=20 \mathrm{mils}$, no IWP)
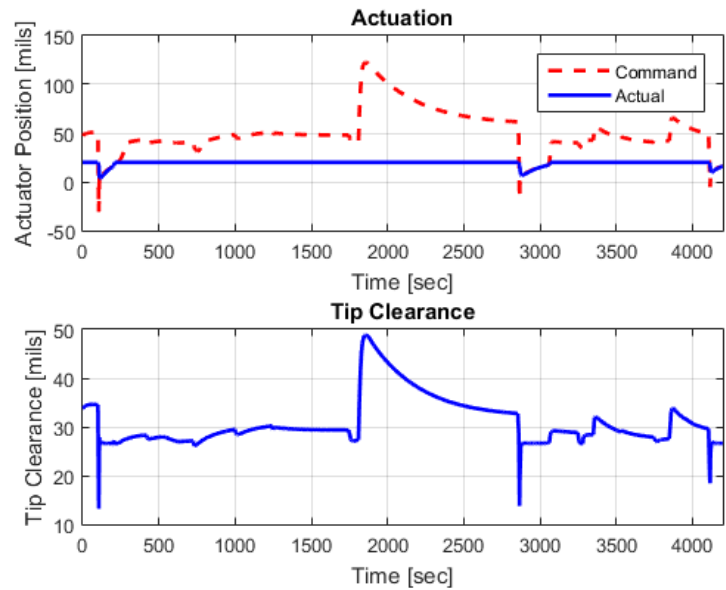

Figure 17. Tip clearance and actuator position response $(B W=0.2 \mathrm{rad} / \mathrm{sec}, R L=4.12 \mathrm{mils} / \mathrm{sec}, S L=20 \mathrm{mils}$, clamping technique) 
To help with these issues, rigorous effort should be put toward designing a robust IWP logic. Alternatively, or in addition, it may be possible to add logic that dictates when the controller itself is active. This may prevent the controller from integrating error during portions of the flight where tip clearance is not of concern, such as ground idle and decelerations. In addition, when such events are detected the integrator could be reset. Another idea is to detect the saturation and temporarily change the commanded tip clearance to the current measured value (assuming it is larger than the desired regulation value) such that no error is accumulated. When the actuator becomes unsaturated the commanded value can be reduced. Another approach would be avoiding the integral windup problem by designing the controller with different techniques, although this may not help in addressing issues with factor (2) listed above. Some control techniques such as model-predictive control could have the potential to alleviate this issue by using knowledge of how the tip clearance is going to react and thus can stay ahead of the system response. In general, predictive control techniques have been shown to be advantageous to tip clearance control in Ref. [26].

The issue of actuator deadband refers to a zone of actuator movement in which no action occurs. It is often the result of slop in gears, linkages, and other mechanical parts in the actuation system. The direct effect of deadband is a delay in the response of the system being actuated when the actuator changes directions. When the actuator is attempting to regulate the output of the system, the deadband can result in oscillations about the set-point as shown in Fig. 18 that can effect steadystate accuracy and transient behavior by changing the initial condition of the actuator system at the start of the transient. Figure 18 captures oscillation during the cruise segment of the flight scenario that was described previously. Deadband can also degrade the performance of the controller. For instance, the oscillations about the commanded tip clearance can result in error accumulation in the PI integrator that can result in an integral-windup issue as is demonstrated in Fig. 19 and 20.

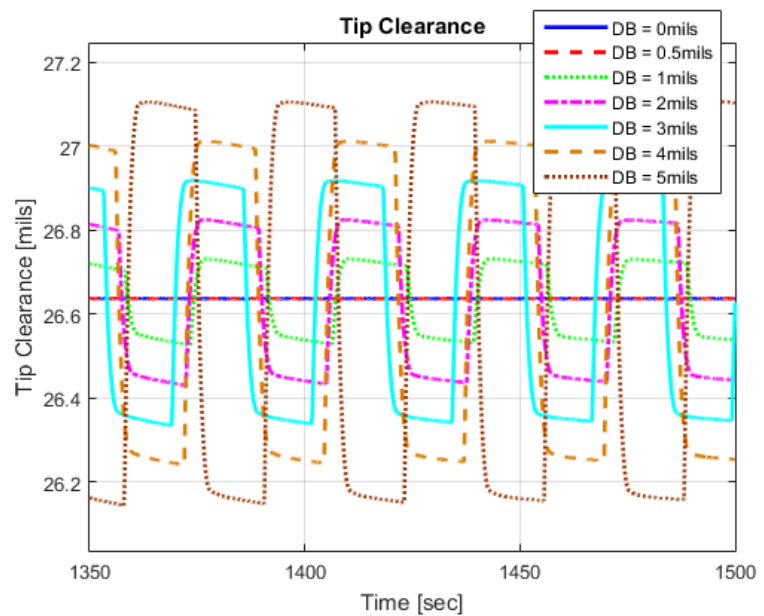

Figure 18. Tip clearance oscillations about the set-point due to deadband
These figures show the tip clearance response before and after the take-off transient of the previously defined flight scenario begins. Imagine integrating the error between the actual tip clearance and the command clearance (at $\sim 26.64 \mathrm{mils}$ ) in Fig. 19 during the time just before the transient begins at $\sim 100 \mathrm{sec}$. The largest error is accumulated by the actuator with the $2 \mathrm{mil}$ deadband and in Fig. 20 and it can be observed that this actuator has the worst performance. Note that anti-windup control logic was used during these simulations. It seems that the small amount of error build up in the integrator is significant enough to make a noticeable impact. Referring to Fig. 18, it can be seen that the period of the oscillations for each actuator is the same but the amplitude increases with deadband. Based on this information and the observation about error accumulation, it can be said that the larger the deadband, the larger the potential for degradation in the actuator response.

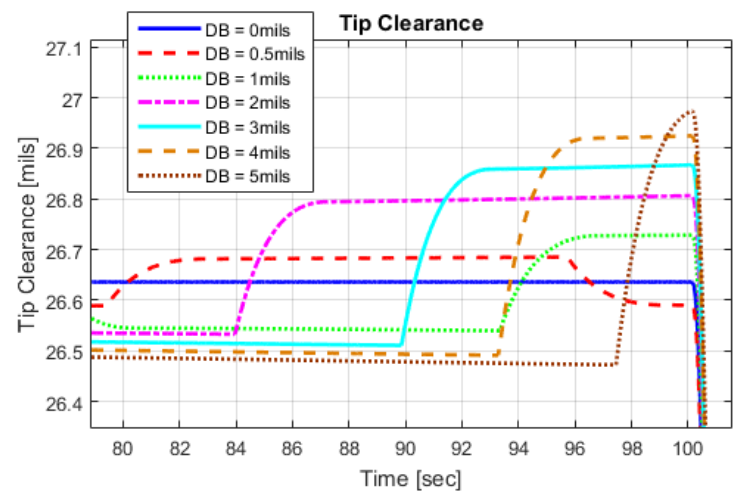

Figure 19. Error accumulation due to deadband

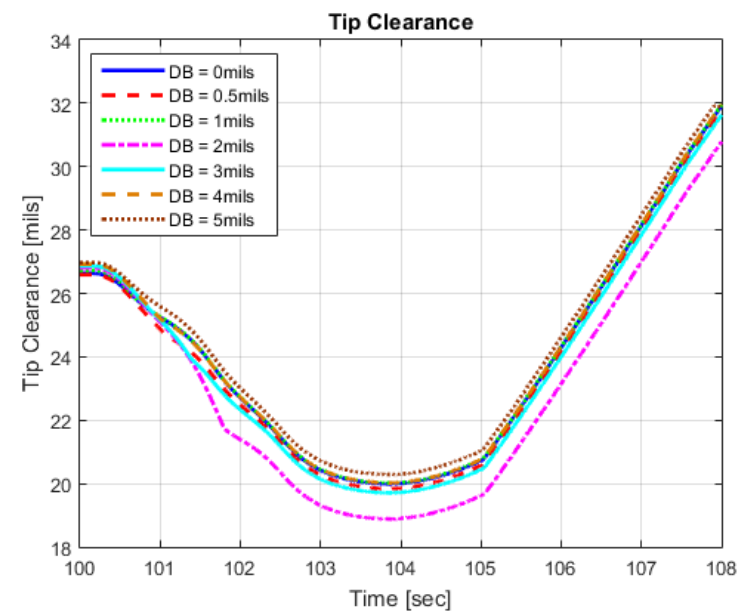

Figure 20. Impact of actuator deadband on the tip clearance response during the take-off transient

Given the inconsistency in the results it makes it hard to predict the impact that a given deadband would have. It is even hard to say what the worst case scenario would be. A few scenarios to consider would be if a tip clearance closing transient begins: 
(1) when the actuator is on the verge of changing direction, moving toward the blade, and its accumulated error is at a maximum

(2) when the actuator is sitting at a position that puts the tip clearance below the commanded value

(3) sometime during the transition from a large tip clearance to a smaller tip clearance when the actuator is moving toward the blade

Investigating this problem further was not within the scope of this research. Therefore, no general recommendations are given here other than to say that less deadband is advantageous. Given that the 2 mil deadband case observed in Fig. 19 and 20 was close to worst case scenario (1) given above and only resulted in $\sim 1$ mil clearance change, 2 mils seems like it could be a reasonable value for the deadband but a more exhaustive study would be needed to say that definitively. Such a study should also address the impact of deadband in combination with other actuator parameters such as bandwidth and rate limit, and consider the impact of the control logic.

Based on the comprehensive findings of this study, an actuator with reasonable characteristics has been chosen and simulated for illustration of its impact on the engine system. The chosen actuator has a bandwidth of $0.5 \mathrm{rad} / \mathrm{sec}$, a rate limit of $5 \mathrm{mils} / \mathrm{sec}$, a range of $40 \mathrm{mils}$, and a deadband of $1 \mathrm{mil}$. Figure 21 compares the closed loop and open loop tip clearance responses. Additionally, Table 2 compares the steady-state cruise performance of the closed loop system to the baseline results in Table 1.

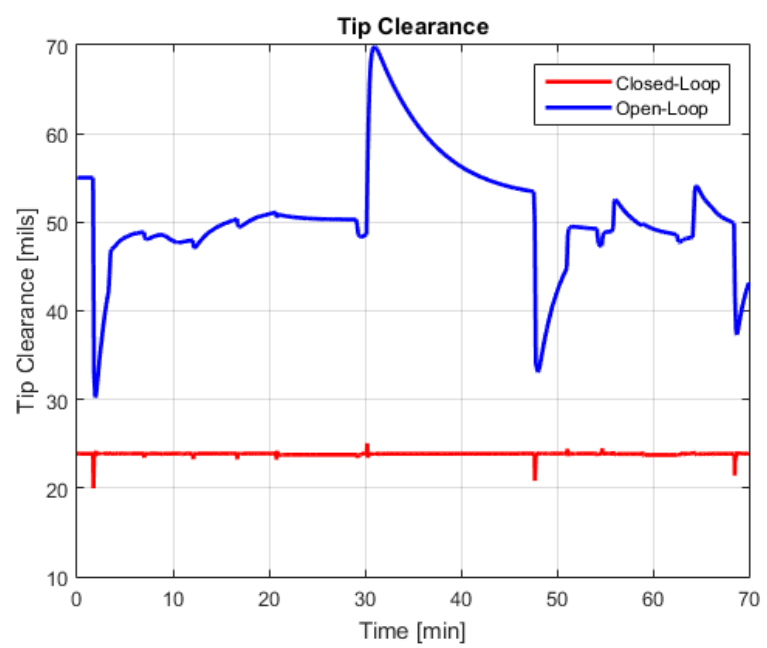

Figure 21. Closed loop and open loop (baseline) tip clearance response comparison

Table 2. Closed loop cruise performance comparison

\begin{tabular}{ll}
\hline \hline Variable & Value \\
\hline Tip Clearance (Closed Loop/Open Loop), mils & $23.77 \mathrm{mils} / 50.31 \mathrm{mils}$ \\
Turbine Efficiency Increase, \% points & $2.22 \%$ \\
Fuel Flow Rate Reduction, \% & $1.28 \%$ \\
Thrust Specific Fuel Consumption Reduction, \% & $1.24 \%$ \\
Turbine Inlet Temperature Reduction, ${ }^{\circ} \mathrm{R}$ & $15.7^{\mathrm{R}} \mathrm{R}$ \\
\hline \hline
\end{tabular}

\section{CONCLUSION}

Improvements to a tip clearance model have been presented and that model has been used to study the needs for turbine tip clearance actuation systems for a modern gas turbine engine. The actuator has been modeled without any assumptions of the type of actuator allowing for general recommendations to be made for actuators in terms of properties such as bandwidth, rate limit, saturation limits, and weight trade. Additionally, investigations were conducted for deadband, integral wind-up, and force requirements. The results of the study suggest that an appropriate active turbine tip clearance control actuator should sustain a bandwidth of 0.1 to $1 \mathrm{rad} / \mathrm{sec}$, rate limits greater than $\sim 4 \mathrm{mils} / \mathrm{sec}$, a range of 40 mils or more, and a relatively small amount of deadband, which is suspected of being on the order of $1 \mathrm{mil}$. The evaluation of actuator requirements was based on the minimum tip clearance achievable with a given actuator while respecting defined safety margins. The study was done using a simulation of an engine that is representative of those currently in use by commercial aircraft. Future commercial engine designs may present a new set of requirements for tip clearance actuation systems and so similar studies need to be pursued to characterize these needs. There is also room to investigate the development of control logic to optimize engine performance through tip clearance modulation. If the tip clearance set-point were to be scheduled based on flight regimes then the clearance and in-turn performance of the engine could be improved further. The issue of integral wind-up and its mitigation, and issues related to saturation are also potentially rich areas of research that were revealed by the analyses conducted here.

\section{ACKNOWLEDGEMENTS}

The authors would like to acknowledge the creators of CMAPSS40k. This work supports the objectives and goals of NASA's Advanced Air Transportation Technology (AATT) Project funded by the Aeronautics Research Mission Directorate (ARMD).

\section{REFERENCES}

[1] Lattime, S.B., and Steinetz, B.M., "Turbine engine clearance control systems: current practices and future directions," American Control Conference, 2001.

[2] Melcher, K.J., and Kryuros, J.A., "Toward a Fast-Response Active Turbine Tip Clearance Control," NASA/TM-2003212627, 2003.

[3] Reyhani, M.R., Alizadeh, M., Fathi, A., and Khaledi, H., "Turbine blade temperature calculation and life estimation - a sensitivity analysis", Power and Propulsion Research, National Laboratory Aeronautics and Astronautics, 2013.

[4] Wiseman, M.W., Guo, T.H., "An investigation of life extending control technologies for gas turbine engines," Proceedings of the American Control Conference, 2001. 
[5] Hughes, C., "NASA Collaborative Research on the Ultra High Bypass Engine Cycle and Potential Benefits for Noise, Performance, and Emissions," NASA/TM-20091274, 2009.

[6] Tong, M. T., Jones, S. M., "An Updated Assessment of NASA Ultra-Efficient Engine Technologies," NASA/TM2005-1163, 2005.

[7] Steinetz, B.M., Lattime, S.B., Taylor, S., DeCastro, J.A., Oswald, J., and Melcher K.J., "Evaluation of an Active Clearance Control System Concept," NASA/TM-2005213856, 2005.

[8] Binghui, J., Zhang, X., and Hou, Y., "Active Control of Turbine Tip Clearance by Fuzzy Parameter Self-setting PID Algorithms," Proceeding of the 8th IEEE International Conference on Automation Science and Engineering, Seoul, Korea, 2012.

[9] DeCastro, J.A., Melcher, K.J., Noebe, R.D., "SystemLevel Design of a Shape Memory Alloy Actuator for Active Clearance Control in the High-Pressure Turbine," NASA/TM-2005-213834, 2005.

[10] Van Ness, D.K., Corke, T.C., Morris, S.C., "Turbine Tip Clearance Flow Control using Plasma Actuators," Proceedings of the 44th AIAA Aerospace Sciences Meeting and Exhibit, Reno, NV, 2006.

[11] May, R.D., Csank, J., Lavelle, T.M., Litt, J.S., and Guo, TH., "A High-Fidelity Simulation of a Generic Commercial Aircraft Engine and Controller," AIAA-2010-6630, AIAA Joint Propulsion Conference, Nashville, TN, July, 2010.

[12] Chapman, J., Kratz, J., Guo, T.H., Litt, J., "Integrated Turbine Tip Clearance and Gas Turbine Engine Simulation," Proceedings of the 52nd AIAA/ASME/SAE/ASEE Joint Propulsion Conference, Salt Lake City, UT, 2016.

[13] Kypuros, J.A., Melcher, K.J., "A Reduced Model for Prediction of Thermal and Rotational Effects on Turbine Tip Clearance," NASA/TM-2003-212226, 2003.

[14] Melcher, K.J., "Controls Considerations for Turbine Active Clearance Control", NASA/CP-2004/212963/Vol. 1.

[15] Kratz, J., Culley, D., Chapman, J., "Approximation of Engine Casing Temperature Constraints of Casing Mounted Electronics," Proceedings of the 52nd AIAA/ASME/SAE/ASEE Joint Propulsion Conference, Salt Lake City, UT, 2016.

[16] Anderson, J.D., Computational Fluid Dynamics: The Basics with Applications, New York: McGraw-Hill, 1995. Print.

[17] Martin, S., Wallace, I., Bates, D. G., "Development and Validation of an Aero-engine Simulation Model for Advanced Controller Design," Proceedings of the 2008 American Control Conference, Seattle, WA, 2008.

[18] Daly, M., Jane's Aero Engines, Issue 28, Ed., Jane's Information Group, London, England, September 2010.

[19] Olsson, W.J., Martin, R.L., "B747/JT9D Flight Loads and Their Effect on Engine Running Clearances and
Performance Deterioration; Nacelle Aerodynamics and Inertial Loads (NAIL)/JT9D Jet Engine Diagnostics Program," NASA CR-165573, 1982.

[20] "All Airborne Aircraft (by aircraft type) with maps $\downarrow$ FlightAware." Flight Aware - . Web. 19 Sept. 2016. http://flightaware.com/live/aircrafttype/

[21] Anderson, J.D., Introduction to Flight: Its Engineering and History, New York: McGraw-Hill, 1978. Print.

[22] "Plane Answers: Minimum Fuel Requirements and Sudden Drops In-flight." Plane Answers - . Web. 20 Sept. 2016. http://gadling.com/2009/02/09/plane-answers-minimumfuel-requirements-and-sudden-drops-inflig/

[23]"Boeing 737-800 - Specification - Technical Data / Description.” Boeing 737-800 Airliner - . Web. 29 Sept. 2016.

http://www.flugzeuginfo.net/acdata_php/acdata_7378_en.p hp

[24]"Boeing 777-300 - Specification - Technical Data / Description.” Boeing 777-800 Airliner - . Web. 29 Sept. 2016.

http://www.flugzeuginfo.net/acdata_php/acdata 7773 en.p hp

[25] Steinetz, B. M., Lattime, S. B., Taylor, S., DeCastro, J. A., Oswald, J., Melcher, K. J., "Preliminary Evaluation of an Active Clearance Control System Concept," Proceedings of the $41^{\text {st }}$ AIAA/ASME/SAE/ASEE Joint Propulsion Conference and Exhibit, Tuscon, AZ, 2005.

[26]Peng, K., Fan, D., Yang, F., Fu, Q., and Li, Y., "Active generalized predictive control of turbine tip clearance for aero-engines," Chinese Journal of Aeronautics, Vol. 26, Issue 5, Oct. 2013, pp. 1147-1155. 